\section{Commentary: Proceed with caution: Right ventricular undersizing in heart transplant}

\author{
Lucas Witer, MD, ${ }^{a}$ and Arman Kilic, $\mathrm{MD}^{\mathrm{b}}$
}

In this issue of the Journal, Kawabori and colleagues ${ }^{1}$ use the United Network for Organ Sharing registry to evaluate the impact of right ventricular undersizing on outcomes of adult heart transplantation. The authors apply previously validated equations for predicting right ventricular mass to define varying degrees of undersizing. The major findings are that right ventricular undersizing was more prevalent in cases using older or female donors and was associated with reduced 1-year survival.

Donor sizing is a critical part of the donor evaluation process in heart transplantation. ${ }^{2}$ Transplant programs and clinicians routinely assess and compare donor and recipient weight and height and place discrepancies in the context of other criteria, including sex combination, overall donor quality (donor age, ejection fraction, presence of left ventricular hypertrophy or coronary artery disease, estimated cold ischemic time, etc), as well as recipient-specific factors such as age, medical urgency, previous cardiac surgery, bridging with a ventricular assist device, and transpulmonary pulmonary gradient. Particularly in borderline cases, many groups also use imaging, including ventricular dimensions on echocardiography and heart and chest cavity size on computed tomography, to better delineate the degree of size mismatch. There is no standardized approach to this important process of matching donors with recipients, and practices can vary

From the a Division of Cardiothoracic Surgery, Medical University of South Carolina, Charleston, SC; and ${ }^{\mathrm{b}}$ Division of Cardiac Surgery, The University of Pittsburgh Medical Center, Pittsburgh, Pa.

Disclosures: A.K. reported Medical Advisory Board, Medtronic, Inc. L.W. reported no conflicts of interest.

The Journal policy requires editors and reviewers to disclose conflicts of interest and to decline handling or reviewing manuscripts for which they may have a conflict of interest. The editors and reviewers of this article have no conflicts of interest.

Received for publication Dec 3, 2020; revisions received Dec 3, 2020; accepted for publication Dec 4, 2020; available ahead of print Dec 13, 2020.

Address for reprints: Arman Kilic, MD, University of Pittsburgh Medical Center, 200 Lothrop St, Suite C-700, Pittsburgh, PA 15213 (E-mail: kilica2@upmc.edu).

J Thorac Cardiovasc Surg 2021;161:1060-1

$0022-5223 / \$ 36.00$

Copyright $₫ 2020$ Published by Elsevier Inc. on behalf of The American Association for Thoracic Surgery

https://doi.org/10.1016/j.jtcvs.2020.12.020

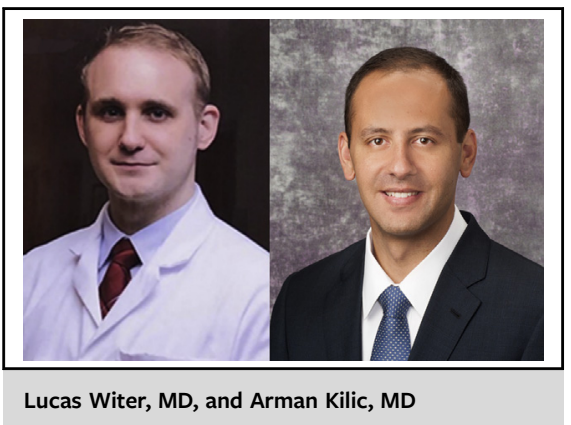

CENTRAL MESSAGE

Right ventricular mass undersiz-

ing in heart transplantation,

found more commonly in older

and female donors, is associated

with worse recipient outcomes

and should be used cautiously.

as much between providers within the same institution as they do between institutions. ${ }^{3}$

The data presented by the authors underscore what many clinicians know, that undersizing by any of these metrics, including the more novel predicted right ventricular mass, subjects the transplanted allograft to increased risk of right heart failure and primary graft dysfunction, with associated multiorgan failure and mortality. What has lagged in this domain but represents an area of significant opportunity is the use of big data, advanced analytics including machine learning, and reconstruction software using medical imaging to better match donor and recipients based on size.

Virtual heart transplantation using 3-dimensional reconstructions based on patient characteristics and imaging studies has shown promise, particularly in pediatric heart transplantation. ${ }^{4}$ In summary, the process entails segmenting and postprocessing recipient images in existing software packages and estimating donor allograft geometries using either available donor images or in cases in which donor images are not available, using a preconstructed virtual library. Although less studied in the adult heart transplant realm, it is feasible that such technology would allow for better estimation of allograft sizing, and with the incorporation of additional recipient and donor data, may provide better insight into the risks of fit-related complications such as primary graft dysfunction. These more sophisticated and innovative approaches may offer an avenue to improving outcomes as well as donor use rates for adult heart transplantation, which remain low at $20 \%$ to $30 \%$ annually in the United States. ${ }^{5}$ 


\section{References}

1. Kawabori M, Critsinelis AC, Hironaka CE, Chen FY, Zhan Y, Thayer KL, et al. Right ventricular undersizing is associated with increased 1-year mortality. J Thorac Cardiovasc Surg. 2021;161:1048-59.e3.

2. Kilic A, Emani S, Sai-Sudhakar CB, Higgins RS, Whitson BA. Donor selection in heart transplantation. J Thorac Dis. 2014;6:1097-104.

3. Khush KK, Ball RL. Great variability in donor heart acceptance practices across the United States. Am J Transplant. 2020;20:1582-96.
4. Plasencia JD, Kamarianakis Y, Ryan JR, Karamlou T, Park SS Nigro JJ, et al. Alternative methods for virtual heart transplantsize matching for pediatric heart transplantation with and without donor medical images available. Pediatr Transplant. 2018;22: e 13290 .

5. Trivedi JR, Cheng A, Gallo M, Schumer EM, Massey HT, Slaughter MS. Predictors of donor heart utilization for transplantation in United States. Ann Thorac Surg. 2017;103:1900-6.
See Article page 1048.

\section{Commentary: Selecting the right cardiac donor}

\author{
Joseph C. Cleveland, Jr, MD
}

It is $02: 30$ and I have just hung up the telephone after a discussion with my on-call heart failure cardiologist. A donor cardiac allograft from a 58-year-old woman who died from a subarachnoid hemorrhage is offered to our transplant center. Her height is $64 \mathrm{in}$, weight $58 \mathrm{~kg}$, and the donor is 750 miles from our center. The recipient is a 28-year-old woman who is 69 in tall and he weighs $81 \mathrm{~kg}$. The recipient is listed as status 2 with an intra-aortic balloon pump and he is a primary sternotomy. Is this donor cardiac allograft the appropriate allograft for our recipient? Will issues with size and sex mismatch affect short- and longer-term outcomes? Will there be another cardiac donor allograft from a larger male donor available in the next few days? All these questions cycle through my mind as the cardiologist and I weigh the risks versus benefits of accepting this donor cardiac allograft.

Kawabori and colleagues ${ }^{1}$ tackle the complex issue of donor cardiac allograft sizing and cardiac transplant recipient outcomes. Their analysis extends the relatively

\footnotetext{
From the Division of Cardiothoracic Surgery, Department of Surgery, University of Colorado Anschutz Medical Center, Aurora, Colo.

Disclosures: The author reported no conflicts of interest.

The Journal policy requires editors and reviewers to disclose conflicts of interest and to decline handling or reviewing manuscripts for which they may have a conflict of interest. The editors and reviewers of this article have no conflicts of interest.

Received for publication Nov 24, 2020; revisions received Nov 24, 2020; accepted for publication Nov 24, 2020; available ahead of print Dec 4, 2020.

Address for reprints: Joseph C. Cleveland, Jr, MD, Division of Cardiothoracic Surgery, Department of Surgery, University of Colorado Anschutz Medical Center, 12631 E 17th Ave, Building A01, Room 6602, MS C-310, Aurora, CO 80045 (E-mail: joseph.cleveland@cuanschutz.edu).

J Thorac Cardiovasc Surg 2021;161:1061-2

$0022-5223 / \$ 36.00$

Copyright (c) 2020 by The American Association for Thoracic Surgery

https://doi.org/10.1016/j.jtcvs.2020.11.140
}

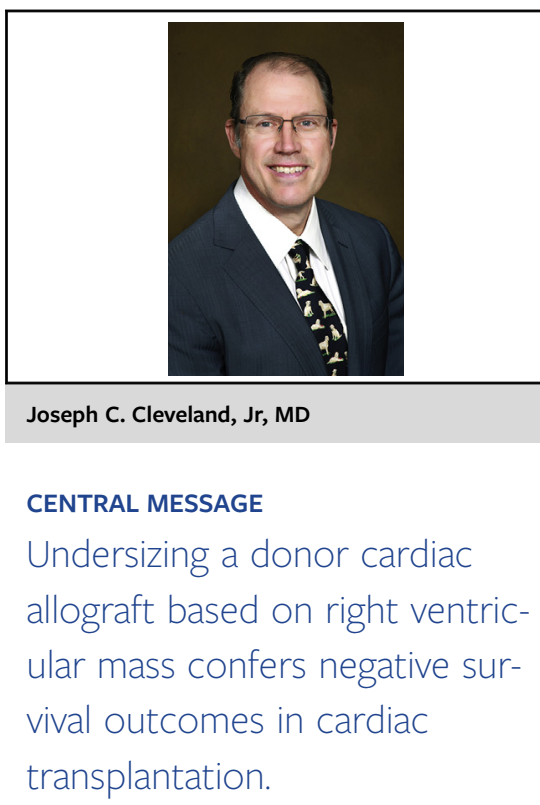

crude concept of matching donor and recipient body weight (within $70 \%$ ) as reflected by current guidelines. $^{2}$ This retrospective analysis of the United Network for Organ Sharing Database of Adult Heart Transplants from 1997-2017 yields more than 38,000 donor-recipient pairs for this study. The authors focus on right ventricular mass (RVM) matching between donor and recipient. In particular, when RVM is undersized in the donor cardiac allograft, how this mismatch negatively influences 1-year outcomes.

There are 3 key messages that emerge. Although RVM constitutes a minority of the total ventricular mass, RVM mismatch profoundly negatively influences 1 -year survival and functional outcomes in cardiac transplant recipients. RVM calculation includes the variables of age and sex. Both of these variables-older donor age and donor female with male recipient-remain well-described risk factors for poor cardiac allograft function and 1-year survival. Lastly, 